\title{
Editorial introduction: Motivation and learning in multiple contexts
}

\author{
Simone Volet • Karen Kimmel
}

Published online: 10 November 2011

(C) Instituto Superior de Psicologia Aplicada, Lisboa, Portugal and Springer Science+Business Media BV 2011

The significance of the context for understanding motivation and learning is not novel in the field of educational psychology (e. g. Anderman and Anderman 2000; Volet and Järvelä 2001). Socio-cognitive, sociocultural and situative perspectives all stress the integration of self and context to understand how individual engagement, learning and development emerge in dynamic, reciprocal interaction in particular social contexts (Greeno 2006; Kagitcibasi 1996; Nolen and Ward 2008; Volet et al. 2009). Yet, with a few exceptions, most of the empirical studies have operationalised context as a single construct, for example, a classroom goal structure, a peer group or teacher style of instruction. Accordingly, such research fails to acknowledge that in real-life situations, individuals are an integral part of multiple social contexts at the same time.

Diverse conceptualisations of context can be found in the literature. For example, contexts have been conceptualised from an ecological systems' perspective, that is, embedded within one another (e.g. small group, classroom, school), thus partly overlapping (Bronfenbrenner 1979; Dasen 2003) or as multilayered (Gurtner et al. 2001; Volet 2001). In the limited empirical literature that has considered the multiplicity of contexts, these have been investigated as cross-fertilising and sometimes conflicting with another (e.g. school, family, peers, Hull and Greeno 2006; Schmid et al. 2005). Across this body of literature, however, contexts are considered as simultaneously and continuously co-defining and coshaping individuals' experiences, motivation, learning and development (Barab and Plucker 2002; Davidson and Phelan 1999; Horn et al. 2008; Kimmel and Volet 2010; Rogoff 2003).

All articles included in this special issue elaborate on how context is conceptualised in their work, and report studies that incorporated multiple contexts in the research design. A variety of theoretical perspectives are used to represent the notion of context. Each article aims to provide a deeper insight into how a particular phenomenon of interest (e.g. engagement, self-efficacy, academic motivation, intercultural experiences) may be perceived or play out differently depending on the situation and the (learning) environment in which it occurs. This extends to how individuals' experiences gained in distinct contexts might be interrelated or possibly foster and/or inhibit each other. The empirical work

\footnotetext{
S. Volet $(\bowtie)$

Murdoch University, Murdoch, Perth, Australia

e-mail: s.volet@murdoch.edu.au

K. Kimmel

RWTH Aachen University, Aachen, Germany

e-mail: karen.kimmel@rwth-aachen.de
} 
reported in the articles uses cross-sectional and/or longitudinal designs as well as a range of quantitative and qualitative methodologies for gaining insights into how individuals' experiences of learning, motivation and achievement are co-shaped by multiple, overlapping contexts that represent the reality of their real-life natural settings. Collectively, this research serves to illustrate the significance of affordances and constraints (Greeno 1998) for individual participation in social activities that are generated in situations where individual, social, cultural and other contextual aspects co-shape and co-regulate participation (Hickey 2003; McCaslin 2004).

Overall, the articles contained in this special issue present a commonly held view that individuals are located within multiple social contexts between which they navigate and participate, and which co-shape their thinking, interactions and experiences. Hence, the seven contributions provide valuable insights into how the interdependence between individuals and their social surroundings (e.g. Gibson 1986; Greeno 1998) co-determines experiences of learning, motivation and interactions.

The authors of the first contribution "Multiple contexts, motivation, and student engagement in the USA and Russia", Elliott and Tudge, build upon Bronfenbrenner's bioecological theory to examine factors which significantly impact on student motivation and engagement in the USA and Russia. The study combines survey and interview data to explore differences in achievement motivation at different levels of the two chosen contexts, taking into account the specific historical and contemporary situation of each country. The significance of facilitative and/or hindering factors for student motivation and engagement situated at the micro- (e.g. classroom, peers, teachers and parents) as well as macro- (e.g. society, broader culture) levels of context are highlighted. Overall, this research demonstrates the usefulness of Bronfenbrenner's bioecological theory as a promising interpretative lens for understanding student motivation and engagement in multiple social contexts. The authors also discuss conceptual and methodological challenges when developing a research design based on Bronfenbrenner's theory.

In the second contribution "Multiple contexts of motivation: a three-dimensional model", Wosnitza and Beltman introduce a heuristic framework of context, which combines multiple levels (micro-, meso-, exo- and macro-), contents (social, material and formal) and perspectives (subjective and objective) of context, each represented by an individual cube. Once assembled, these cubes form the components of a comprehensive, multifaceted graphical representation of context. Several empirical studies illustrate how distinct combinations of levels, content and perspectives of context can shed a different light on learning and motivation across settings as diverse as academia, sports and music. These studies combine quantitative and qualitative methodologies ranging from questionnaires, interviews and observations to graphical illustrations. The three-dimensional model proposed by Wosnitza and Beltman provides a useful heuristic framework for considering how multiple aspects of contexts can be operationalized and organised in a systematic manner. The authors conclude by discussing some conceptual and methodological issues related to each dimension of the model. They stress the necessity of representing multiple, overlapping contexts to comprehensively understand the complexity of learning and motivation in natural surroundings.

The authors of the third contribution "Transferring motivation from educational to extramural contexts: a review of the trans-contextual model", Hagger and Chatzisarantis, present a complex and coherent model to reveal how autonomous motivation towards physical activities in educational contexts can transfer to related activities in noneducational, extramural contexts. The authors ground their model in an integrated, multitheory approach combining tenets from self-determination and planned behaviour theories. 
They use a range of prospective and intervention research adopting the trans-contextual model to demonstrate the transfer of motivation toward physical activities from one context to the other (i.e. from educational to leisure time contexts). Their empirical work revealed that perceived autonomy support in the physical education context predicted autonomous motivation in the same context, which in turn was found to affect autonomous motivation in a leisure time context. Overall, the paper presents evidence supporting the motivational constructs from the model to gain a better understanding of the mechanisms behind the impact of perceived autonomy support in physical education on leisure time physical activity behaviour. The authors discuss the applicability of their trans-contextual model to other education contexts such as science and language learning and individuals' motivation to engage in these subjects in extramural contexts. Hence, this highlights the potential of the model for designing intervention research in the field of motivation transfer.

The fourth contribution, "Learning in multiple contexts: are there intra-, cross- and transcontextual effects on the learner's motivation and help-seeking?" by Gurtner, Gulfi, Genoud, de Rocha and Schumacher, examines how apprentices' learning motivation and readiness to seek help in the so-called dual-track system, i.e. in school and company settings, evolve similarly or differently over the duration of their training in these specific learning contexts. In their research, learners' motivation was operationalised in terms of self-efficacy and motivation to learn in the distinct contexts (i.e. company and school, but also including a distinction between general education courses and specific courses for the chosen profession). The authors report two studies, which both used a combination of longitudinal and cross-sectional designs, and survey as well as interview methodologies. These studies explored three different types of effect related to context, including intracontextual stability, cross-contextual influences and trans-contextual interactions. The findings highlight how learning experiences can differ across learning contexts, and how experiences in one context can form and shape individuals' intentions and motivations to learn or seek help in another context. Overall, these empirical studies illustrate how individual experiences gained in distinct learning contexts can cross-fertilise, sustain but also inhibit each other, hence powerfully strengthening the case for acknowledging the multiple, overlapping nature of real-life settings when conducting research on motivation and learning.

In the fifth contribution "Intercultural interactions at university: new insights from an activity theory and multiple context perspective", Kimmel and Volet explore the complex, changing and context-sensitive nature of students' intercultural experiences from a theoretical framework that combines central tenets from activity theory with a multiple contexts perspective. While activity theory emphasises the evolving and complex interrelations between individuals and their natural surroundings (in this article conceptualised as activity systems), the multiple context stance highlights the overlapping and embedded nature of these surroundings. A series of empirical studies that incorporated quantitative methodologies for identifying meaningful patterns and qualitative methodologies for gaining experiential insights into students' intercultural experiences across multiple social contexts (i.e. formal on campus and informal, off campus) are presented. These studies reveal the powerful interplay of contextual affordances and constraints generated within the formal educational and informal social contexts, which co-shape students' cognitive, motivational and affective experiences with their culturally diverse peers through the complexities of their daily life. This research also demonstrates the usefulness of a combined activity theory and multiple context perspective for gaining a better understanding of the complex, interdependent and context-sensitive nature of students' intercultural experiences. 
The authors of the sixth contribution "Cultural identity and academic motivation", Urdan and Munoz, examine the association between cultural identity and academic motivation for students with immigrant and non-immigrant backgrounds. Their empirical work combines multiple methods ranging from survey to interview data, but also implicit association tests to elicit and examine participants concepts of preferred cultural identity, academic motivation (i.e. academic self-concept, valuing of academics, feelings of belonging to the university) and associations among success and failure for Hispanic and Caucasian ethnic groups. The findings reveal between-group differences in students' subjectively perceived importance of their cultural identity, as well as differences in the relationship between cultural identity and academic motivation. Interestingly, the implicit association tests showed identical results for students with immigrant and non-immigrant backgrounds, both groups implicitly associating success more strongly with Caucasians than with Hispanics. The authors discuss their findings in light of the multiple contexts (e. g. family, school, peers) in which students operate throughout their daily lives and stress how the boundaries between these distinct contexts create particular challenges for individuals with immigrant backgrounds. This research highlights the significant role of students' cultural identity as a core element of their overall identity with important implications for their academic motivation.

This issue concludes with the contribution "Methods for taking a situative approach to studying the development of motivation, identity and learning in multiple social contexts" by Nolen, Ward and Horn. This article concentrates on the methodological implications of studying the interconnected and evolving nature of motivation, identity and learning across diverse social contexts. The authors discuss a range of methodological issues and challenges encountered when using ethnographic methodologies. In particular, they elaborate on the structuring of longitudinal interviews, the interdependence between interview and observational data, and the importance of treating interviews as social contexts where participants and interviewers negotiate and co-construct meanings of motivation, identity and learning. The authors embed their discussion and elaborations within empirical illustrations of two case studies from their own research. Their analysis reveals how participants' motivation, identity and learning evolved over time alongside partly overlapping and at times conflicting affordances and constraints of university, field placements and the schools they worked at. The combination of observational and interview data enabled the authors to trace and interpret changes in participants' motivation as well as their subjective interpretations of their learning, identity and motivation. This paper provides new insights into how the evolving, complex and context-sensitive nature of motivation, identity and learning can be studied when using innovative methods of data collection and analysis.

To conclude, this special issue provides a differentiated and valuable insight into how motivation and learning can be better understood when acknowledging the overlapping and multilayered contexts that individuals are part of and navigate through their everyday lives. The challenge of researching the complex and multifaceted nature of context is reflected in contributors' attempts to either integrate several theoretical perspectives or to develop new conceptual models to frame their empirical work. Although the importance of multiple contexts for motivation and learning is a dominant theme in all papers, the conceptualisation of context varies widely, ranging from macro-level (historically derived) societal values and cultural practices to a more meso- (i.e. educational systems and assessment practices) and micro-level (i.e. family, peer group). The adoption of cross-sectional and longitudinal designs combined with quantitative and qualitative methods provide promising starting points from which research adopting a multiple context perspective can be conducted. 
Hopefully, these examples will stimulate and encourage further research, contributing to a more comprehensive understanding of motivation and learning in multiple and multifaceted social contexts. Researching and interpreting individuals' cognitive, motivational and social experiences of learning in relation to the various contextual affordances and constraints that natural surroundings provide at individual, proximal as well as at broader, distal levels acknowledge the inherent interdependence of individuals and contexts. Such research has the potential to lead to a fuller and deeper understanding of how individuals' cognitions, motivations and behaviours evolve through reciprocal interplays with the multiple social contexts that individuals participate in on a daily basis.

Acknowledgement We would like to thank all the reviewers for their valuable advice and suggestions for the preparation of this special issue.

\section{References}

Anderman, L. H., \& Anderman, E. M. (2000). Considering contexts in educational psychology: introduction to the special issue. Educational Psychologist, 35(2), 67-68.

Barab, S. A., \& Plucker, J. A. (2002). Smart people or smart contexts? Cognition, ability, and talent development in an age of situated approaches to knowing and learning. Educational Psychologist, 37(3), $165-182$.

Bronfenbrenner, U. (1979). The ecology of human development: experiments by nature and design. Cambridge: Harvard University Press.

Dasen, P. R. (2003). Theoretical frameworks in cross-cultural developmental psychology: an attempt at integration. In T. S. Saraswathi (Ed.), Cross-cultural perspectives in human development: theory, research and applications (pp. 128-165). New Delhi: Sage.

Davidson, A. L., \& Phelan, P. (1999). Students' multiple worlds: an anthropological approach to understanding students' engagement with school. In T. C. Urdan (Ed.), Advances in motivation and achievement: the role of context (Vol. 11, pp. 233-273). Stanford: JAI Press Inc.

Gibson, J. J. (1986). The ecological approach to visual perception. Hillsdale: Erlbaum. Original work published 1979.

Greeno, J. G. (1998). The situativity of knowing, learning, and research. American Psychologist, 53(1), 5-26.

Greeno, J. G. (2006). Learning in activity. In R. K. Sawyer (Ed.), The Cambridge handbook of the learning sciences (pp. 79-96). Cambridge: Cambridge University Press.

Gurtner, J.-L., Monnard, I., \& Genoud, P. A. (2001). Towards a multilayer model of context and its impact on motivation. In S. Volet \& S. Järvelä (Eds.), Motivation in learning contexts: theoretical advances and methodological implications (pp. 189-208). Amsterdam: Elsevier.

Hickey, D. T. (2003). Engaged participation versus marginal nonparticipation: a stridently sociocultural approach to achievement motivation. The Elementary School Journal, 103(4), 401-430.

Horn, I. S., Nolen, S. B., Ward, C., \& Campbell, S. (2008). Developing practices in multiple worlds: the role of identity in learning to teach. Teacher Education Quarterly, Summer, 61-72

Hull, G., \& Greeno, J. (2006). Identity and agency in non-school and school worlds. In Z. Bekerman, N. C. Burbules, \& D. Silberman-Keller (Eds.), Learning in places: the informal educational reader (pp. 7797). New York: Peter Lang.

Kagitcibasi, C. (1996). Family and human development across cultures: a view from the other side. Hillsdale: Lawrence Erlbaum.

Kimmel, K., \& Volet, S. (2010). Significance of context in university students' (meta)cognitions related to group work: a multi-layered, multi-dimensional and cultural approach. Learning and Instruction, 20(6), 449-464.

McCaslin, M. (2004). Co-regulation of opportunity, activity, and identity in student motivation: elaborations on Vygotskian themes. In D. McInerney \& S. V. Etten (Eds.), Big theories revisited (Vol. 4, pp. 249274). Greenwich: Information Age.

Nolen, S., \& Ward, C. J. (2008). Sociocultural and situative approaches to studying motivation. In M. Maehr, S. Karabenick, \& T. Urdan (Eds.), Social psychological perspective on motivation and achievement (Advances in motivation and achievement, Vol. 15, pp. 425-460). London: Emerald.

Rogoff, B. (2003). The cultural nature of human development. New York: Oxford University Press. 
Schmid, S., Hofer, M., Dietz, F., Reinders, H., \& Fries, S. (2005). Value orientations and action conflicts in students' everyday life: an interview study. European Journal of Psychology of Education, 20(3), 243257.

Volet, S. E. (2001). Understanding learning and motivation in context: a multidimensional and multi-level cognitive-situative perspective. In S. Volet \& S. Järvelä (Eds.), Motivation in learning contexts: theoretical advances and methodological implications (pp. 57-82). Amsterdam: Elsevier.

Volet, S. E., \& Järvelä, S. (Eds.). (2001). Motivation in learning contexts: theoretical advances and methodological implications. Amsterdam: Elsevier.

Volet, S. E., Summers, M., \& Thurman, J. (2009). High-level co-regulation in collaborative learning: how does it emerge and how is it sustained? Learning and Instruction, 19(2), 128-143.

Simone Volet. School of Education, Murdoch University, South Street, Murdoch 6150, Australia. E-mail: s.volet@murdoch.edu.au

Current themes of research:

Learning. Motivation. Self and social regulation. Metacognition. Collaborative learning. Cultural issues in learning.

Relevant publications:

Järvelä, S., Volet, S. E., \& Järvenoja, H. (2010). Research on motivation in collaborative learning: Moving beyond the cognitive-situative divide and combining individual and social processes. Educational Psychologist, 45(1), 15-27.

Summers, M., \& Volet, S. E. (2010). Group work does not necessarily equal collaborative learning: Evidence from observations and self-reports. European Journal of Psychology of Education, 25(4), 473-492.

Volet, S. E., Summers, M., \& Thurman, J. (2009). High-level co-regulation in collaborative learning: How does it emerge and how is it sustained? Learning and Instruction, 19, 128-143.

Volet, S. E., Vauras, M., \& Salonen, P. (2009). Self- and social regulation in learning contexts: An integrative perspective. Educational Psychologist, 44(4), 215-226.

Volet, S. E., \& Karabenick, S. (2006). Help-seeking in cultural context. In S. Karabenick \& R. Newman (Eds.), Help seeking in academic settings: Goals, groups and contexts (pp. 117-150). Mahwah, NJ: Erlbaum.

Karen Kimmel. RWTH Aachen, Institute of Education, Eilfschornsteinstr. 7, D-52062 Aachen, Germany. E-mail: karen.kimmel@rwth-aachen.de

Current themes of research:

Student emotions and motivation. Group work. Intercultural interactions at university.

Relevant publications:

Kimmel, K., \& Volet, S. E. (in press). University students' perceptions of and attitudes towards culturally diverse group work: Does context matter? Journal of Studies in International Education. doi:10.1177/ 1028315310373833

Kimmel, K., \& Volet, S. E. (in press). Significance of context in university students' (meta)cognitions related to group work: A multi-layered, multi-dimensional and cultural approach. Learning and Instruction, 20 (6), 449-464.

Kimmel, K., \& Volet, S. E. (2010). Culture in motivation research: A challenging and enriching contribution. In P. Peterson, E. Baker \& B. McGaw (Eds.), International Encyclopedia of Education (Vol. 6, pp. 576584). Oxford: Elsevier. 